\title{
Multiple cerebral metastases and metastatic aneurysms in patients with left atrial Myxoma: a case report
}

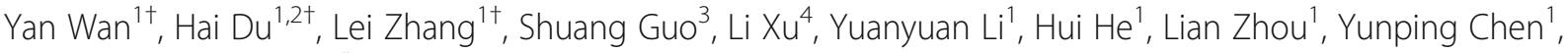 \\ Ling Mao ${ }^{1}$, Huijuan $\mathrm{Jin}^{1 *}$ and $\mathrm{Bo} \mathrm{Hu}{ }^{1}$
}

\begin{abstract}
Background: Cardiac myxoma is the most common benign cardiac tumor. Brain metastases or multiple cerebral aneurysms are extremely rare, especially for the case of both complications. Brain metastases are usually found at the same time or few months after the diagnosis or surgical removal of cardiac myxoma
\end{abstract}

Case presentation: We describe a case of patient, operated for a cardiac myxoma, who presented multiple central nervous system metastases associated, cerebral aneurysms and subsequent intracerebral hemorrhage

Conclusions: The long-term follow-up of the patients with atrial myxoma even after complete surgical excision is recommended, especially for the patient with central nervous system manifestations before atrial myxoma excision

Keywords: Atrial myxoma, Cerebral metastasis, Metastatic aneurism, Hemorrhage

\section{Background}

Myxomas are the most common tumors of the heart, representing $83 \%$ of all primary cardiac tumors with nearly $75 \%$ of them arising in the left atrium [1]. Left atrial myxomas are considered highly curable with excellent outcomes in the long-term. Complete resection of cardiac myxoma and its cardiac appendages can cure cardiac myxoma, but incomplete resection, multifocal tumors and embolism caused by tumors are important factors for its recurrence [2].

Cardiac myxoma may cause a wide variety of complications including cardiac obstructive symptoms, systemic embolism and cerebral infarcts [3, 4]. The central nervous system (CNS) is one of the most susceptible areas of embolization most often resulting in ischemic strokes. Cerebral metastatic, intraparenchymal hemorrhage and oncotic aneurysm are uncommon neurological sequelae of atrial myxoma. Since the persistent risk of brain metastases and aneurysms formation, the early diagnosis and intervention is desirable. We reported a case of postoperative

\footnotetext{
* Correspondence: jinhuijuan1983@163.com

${ }^{\dagger}$ Yan Wan, Hai Du and Lei Zhang contributed equally to this work. 'Department of Neurology, Union Hospital, Tongji Medical College, Huazhong University of Science and Technology, Wuhan 430022, China Full list of author information is available at the end of the article
}

patient with left atrial myxoma excision associated with the multiple central nervous system metastases, cerebral hemorrhage and myxomatous aneurysms.

\section{Case presentation}

A 39 years old woman with a background history of left atrial myxoma with total tumor excision done on November 24, 2017, presented to us on June 21, 2018 with progressive headache associated with blurred vision, nausea and vomiting which was lasting for 1 month. There was no history of fever, trauma or seizure. Brain computed tomography (CT) showed heterogeneous hemorrhagic lesions surrounded by edema. The lesions were spread through both hemispheres with the largest one in the left frontal lobe about $2.4 * 2.2 \mathrm{~cm}$ in diameters (Fig. 1). Magnetic resonance imaging including MRI, MRA and SWI confirmed the presence of multiple brain metastases of myxoma and cerebral aneurysm formation from myxoma involving the bilateral anterior cerebral artery (ACA) and middle cerebral artery (MCA), right posterior cerebral artery (PCA) and superior cerebellar artery (SCA) (Fig. 2). Subsequent ${ }^{18}$ F-FDG PET-CT was performed to exclude malignancy (Fig. 3). The echocardiographic showed no recurrence of the atrial myxoma.

(c) The Author(s). 2019 Open Access This article is distributed under the terms of the Creative Commons Attribution 4.0 International License (http://creativecommons.org/licenses/by/4.0/), which permits unrestricted use, distribution, and 

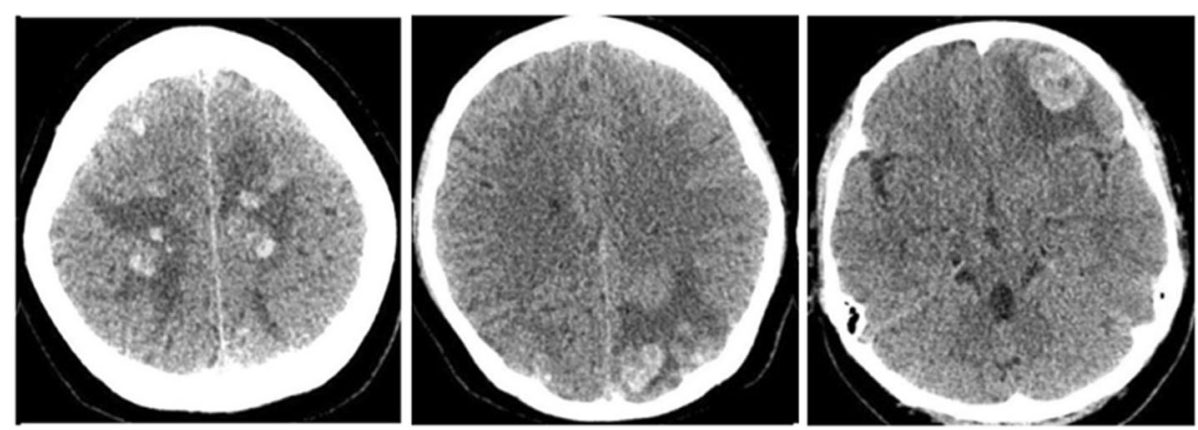

Fig. 1 CT brain image shows multiple hemorrhagic lesions surrounded by edema

On July 12, 2018, the patient was admitted to the Beijing Tiantan Hospital for treatment. A left frontotemporal craniotomy was performed. The left ACA arterial aneurysms, which were responsible for intracranial hemorrhage in the left frontal lobe lesion, were neurosurgical clipping and a little bit of the frontal tissue $(4 * 4 * 8 \mathrm{~mm})$ was excised for histological examination. For safety of the patient, other lesion sites involving the right ACA and the bilateral MCA, right PCA and SCA were not treated by surgery. And they found myxoma cells in the brian tissue by histological examination confirming the cerebral metastases despite 7 months having passed since the cardiac myxoma was resected. Hematoxylin and eosin staining of both tissue disclosed typical atrial myxoma cells, embedded in a loose myxoid matrix in the resected tissue (Fig. 4).

After the surgery, the patient received antiepileptic, antiemetic and rehydration treatment and other symptomatic treatments. Her headache, blurred vision, nausea and vomiting disappeared gradually. Ten days later, she had a very good recovery and discharged from the hospital. After then, she received antiplatelet treatment and
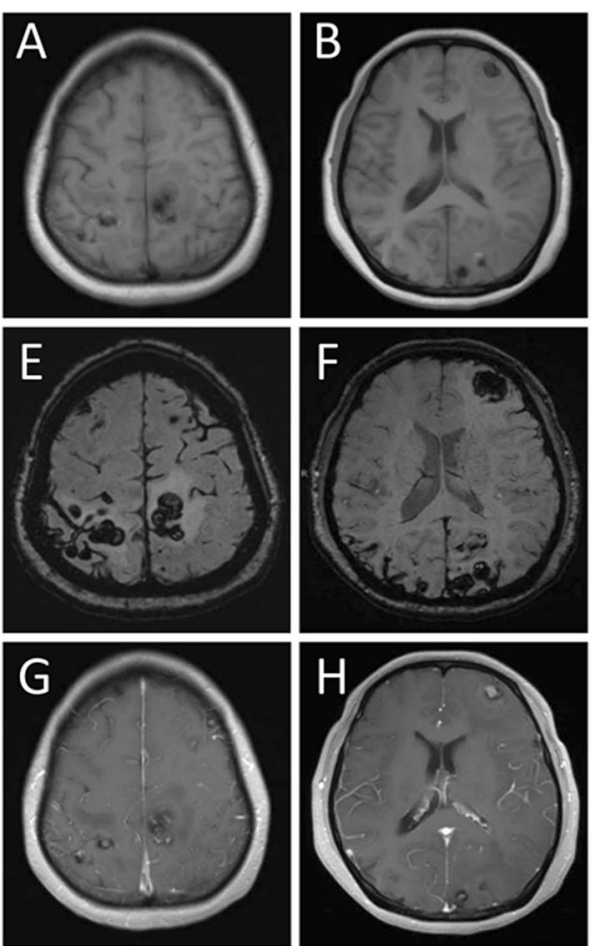
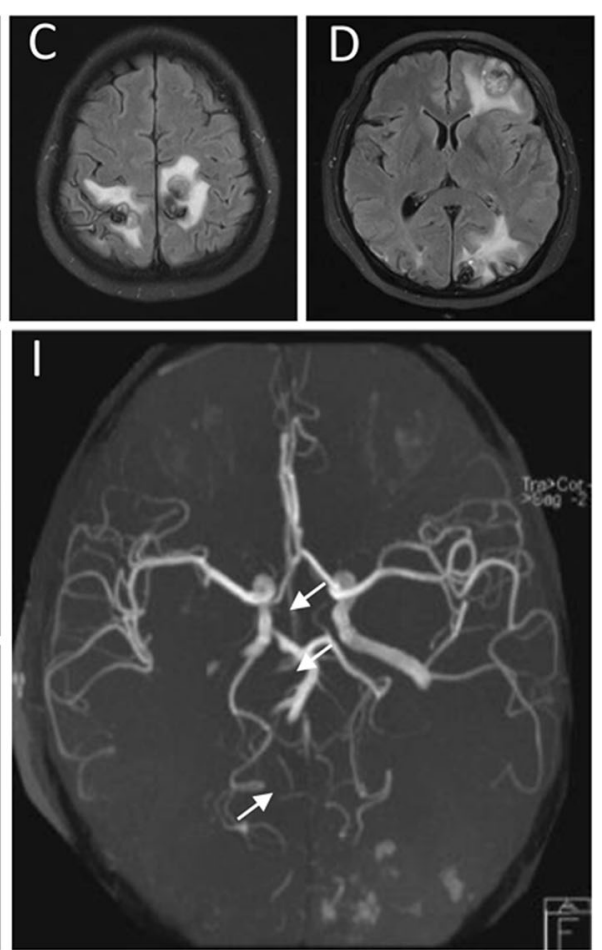

Fig. 2 MRI brain images show multiple brain metastases of myxoma, hemorrhage and cerebral aneurysm formation from myxoma. a-b The axial T1-weighted images. c-d The axial T2-weighted flair images show multiple nodules or mass shadow. e-f The axial SWI images shows multiple cerebral hemorrhage. $\mathbf{g}$-h Magnetic resonance enhanced scan showed heterogeneous reinforcement. $\mathbf{i}$ The MRA images for aneurysms 


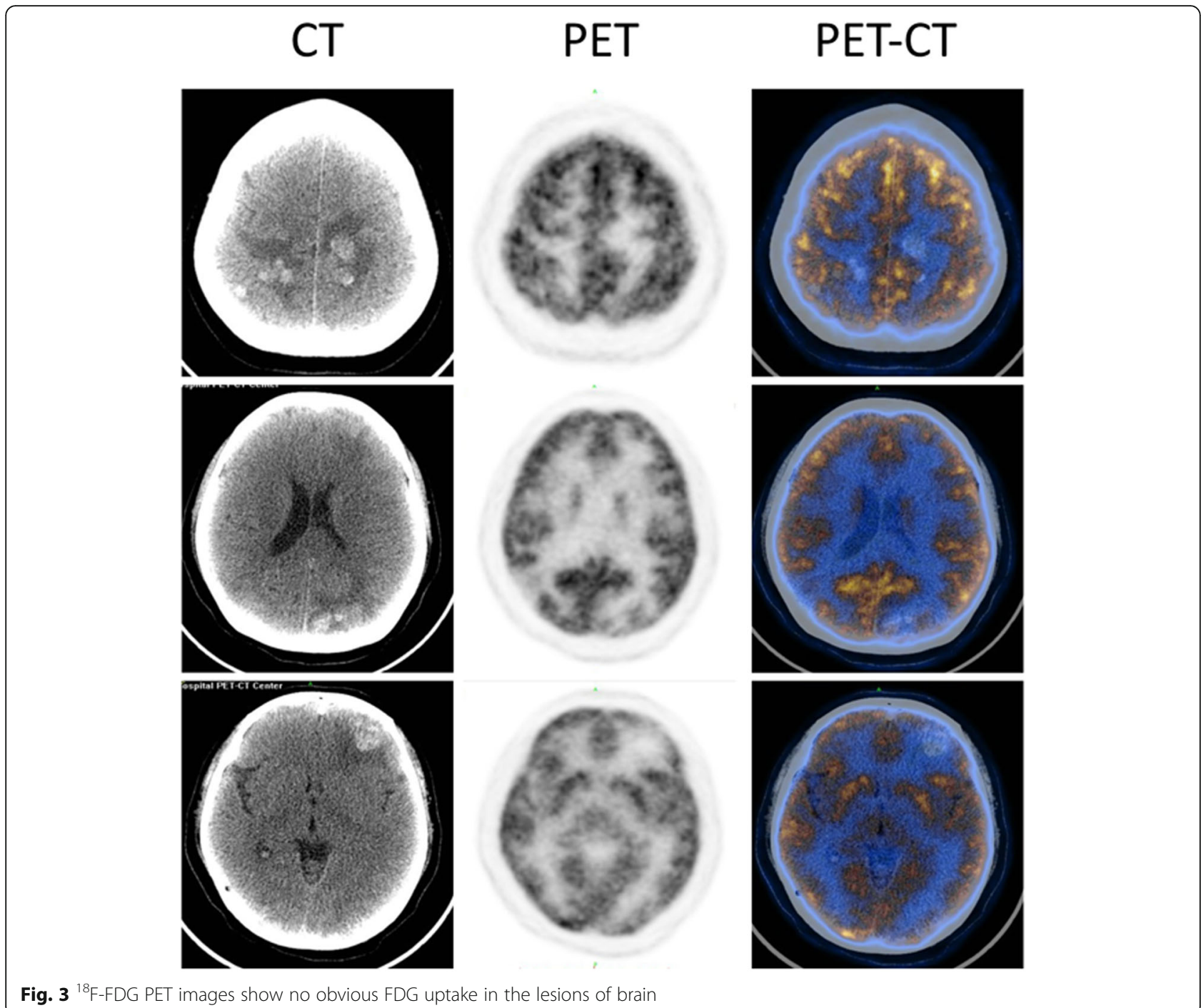

a follow-up observation. In May, 2019, she received reexamination of magnetic resonance imaging including MRI and MRA. Results showed that the brain lesions became smaller, but edema around them became larger than before and the metastatic aneurysms rarely changed (Fig. 5). However, no headache, nausea, vomiting, and other neurological symptoms appeared, so she kept the antiplatelet treatment and follow-up observations.

\section{Discussion and conclusion}

Cardiac myxoma represents mostly benign, slowly proliferating tumor which are believed to derive from multipotent mesenchymal cells of the endocardium [5]. It may present with many clinical syndromes outside the cardiac events. It was reported that about $20-30 \%$ of patients with atrial myxoma had neurological complications $[3,6,7]$. The CNS manifestations include progressive headache, nausea or vomiting due to the increase of intracranial pressure, limbs or body weakness or numbness and new onset of seizure [6]. In the majority of cases such complications appear in rather young patients and are usually caused by cerebral embolism and subsequent cerebral infarcts [7, 8]. Cerebral metastatic, aneurysm formation and subsequent subarachnoid or intracerebral hemorrhage are rare but well-known complications of atrial myxoma in adults [9]. Furthermore, aneurysms secondary to myxoma can be a delayed presentation and can be found before resection of myxoma or even after resection of myxoma [10,11], as in this case. So it is necessary to have a screening with regard to cerebral complications in patients with atrial myxoma. Imaging studies as CT, MRI and cerebral angiography should be performed in every patient with atrial myxoma to detect aneurysms and 

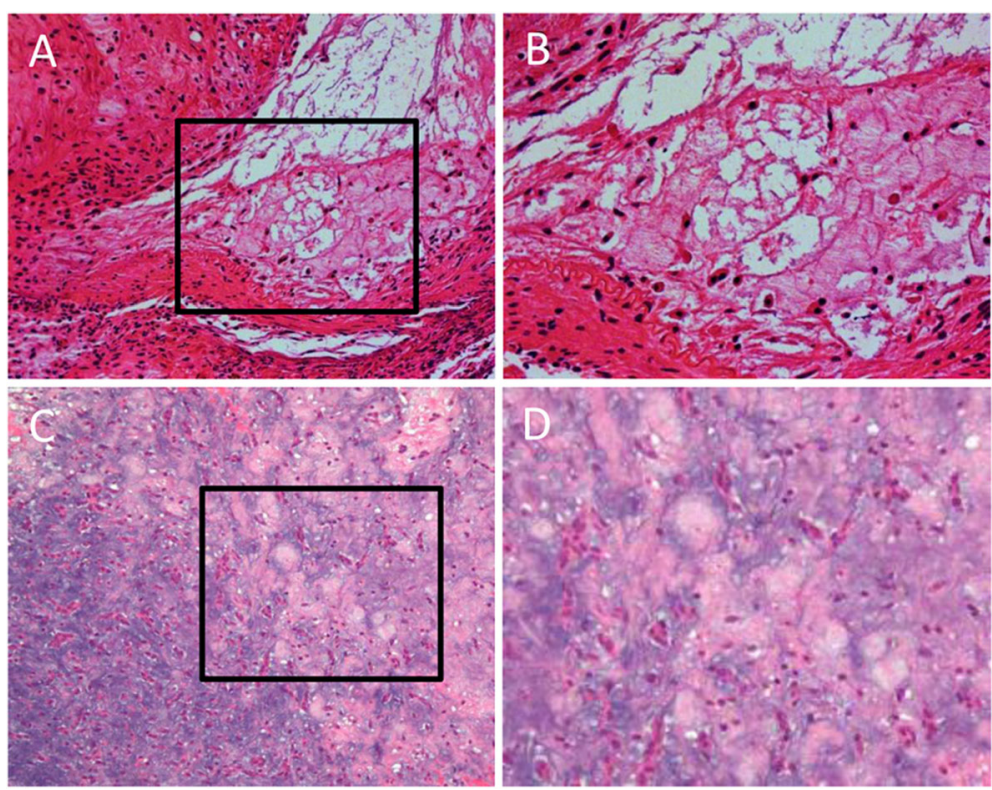

Fig. 4 Photomicrographs of the excised left frontal tissue section and cardiac tissue revealing the presence of myxoma cells. H \& E. a Low-power magnification of brain tissue $(\times 20)$. b High-power magnification of the area in A surrounded by the black line $(\times 40)$. c Low-power magnification $(\times 20)$ of cardiac tissue. $\mathbf{d}$ High-power magnification of the area in $C$ surrounded by the black line $(\times 40)$

cerebral lesion. The echocardiography is also suggested for every patient presenting a cerebral infarction with aneurysm [12].

Brain metastases are usually found at the same time or few months after the diagnosis of cardiac myxoma. Other systemic metastases of cardiac myxoma concomitant with the brain have been reported in kidney, pancreas, bone, muscles, skin and stomach $[4,13]$. All of these metastases can be explained by the dislodgement of the friable and spongy component of the atrial myxoma into the systemic circulation [14]. The myxomatous aneurysm formation process remains unclear. Three causes of cerebral aneurysm formation have been proposed $[14,15]$. One is the vascular damage hypothesis. They postulated that large myxomatous emboli cause vascular occlusion and perivascular damage with subsequent scarring and pseudoaneurysm formation. The other cause is the cerebral vessels are infiltrated by myxoma cells via vasa vasorum causing the destruction of arterial wall architecture, which is similar to the mechanism of mycotic aneurysms. The last cause that has been suggested is the neoplastic process. Several authors have observed myxomatous cells in the aneurysmal vessel. They hypothesized the myxomatous cells could remain viable and penetrate intact or damaged endothelium at the site of final lodgement, with subintimal growth, destruction of the wall, and fibroblastic proliferation. This neoplastic process was accompanied by connective tissue proliferation and a mild inflammatory reaction, and neovascularization in the affected arterial wall may lead to minor bleeding.

Cardiac surgery is the method of choice in treating myxoma [16]. And once the diagnosis is established, surgery should be performed promptly to reduce the possibility of embolic complications or sudden death. For the surgery, three important points should be noted to prevent recurrence: 1) multifocal tumors in heart chambers should not be omitted during operation [17]; 2) cardiac appendages should be removed, sutured and repaired if necessary [18-21]; 3) tumors must be avoided from fragmentation and embolization [19].

Nevertheless, there are no precise guidelines for possible treatment procedures of neurological complications $[5,14]$. The use of anticoagulants or antiplatelet agents should be considered in order to prevent further emboli. Surgery is appropriated in cases with few isolated aneurysm or brain metastases or when one of the lesions is life threatening. Moreover, chemotherapy with doxorubicin or ifosfamide with or without radiotherapy of the whole brain could be administrated to patients with multiple brain metastases in order to obtain a longer period of time without recurrence [22]. Furthermore, it is noted that most of the aneurysms are fusiform in shape, and clipping or coiling treatment can be limited. Though there are successful cases of endovascular coiling for enlarging aneurysms, overall evidence documenting stability of cerebral aneurysms over several years 

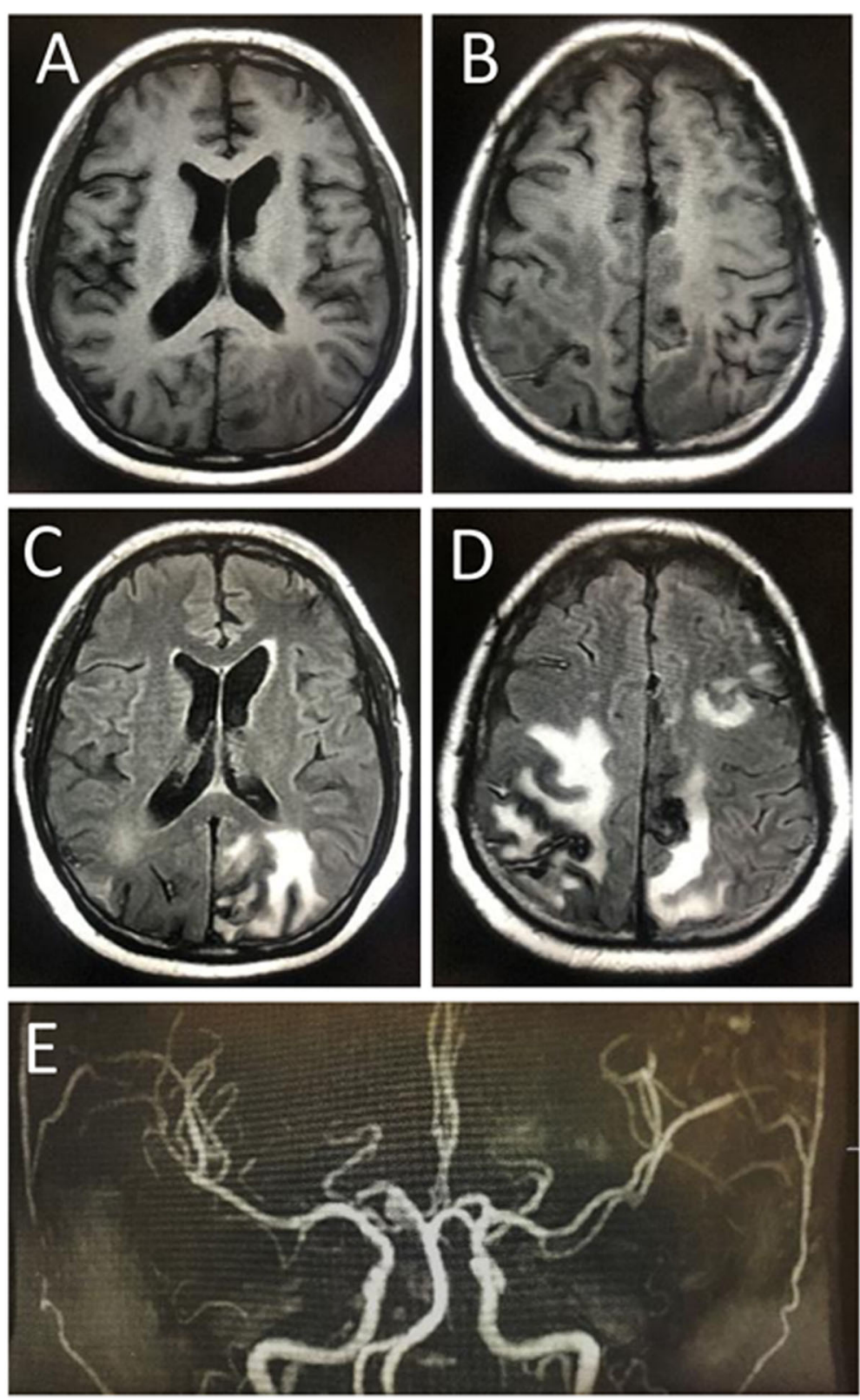

Fig. 5 MRI brain images from follow-up examination. a-b The axial T1-weighted images. $\mathbf{c}-\mathbf{d}$ The axial T2-weighted flair images show multiple nodules or mass shadow. e The MRA image for aneurysms

gives support to conservative treatment management options [12, 23-25].

Thus, long term follow-up of the patients with atrial myxoma even after complete surgical excision is recommended [16]. Thorough explanation of the potential risks of recurrence of the cardiac tumor, the late development and enlargement of cerebral lesions are necessary. Vigorous work-up must be pursued if the patient again becomes symptomatic or develops new central nervous system manifestations.

\section{Abbreviations}

ACA: Anterior cerebral artery; CNS: Central nervous system; CT: Computed tomography; MCA: Middle cerebral artery; PCA: Right posterior cerebral artery; SCA: Superior cerebellar artery

\section{Acknowledgements}

We would like to thank the patient and her family for the participation and approval in this study.

\section{Authors' contributions}

YW, HD and LZ1 (the 3rd in author list) contributed to this work by obtaining the clinical information and drafting the manuscript. SG and LX contributed to the pathological diagnosis. YYL, HH, LZ2 (the 8th in author 
list) and YPC contributed to conception, design analysis and interpretation, and critically revised the manuscript. LM, HJJ and BH were involved in processing, analyzing and interpreting data and revising the manuscript. All authors read and approved the submission of the manuscript

\section{Funding}

This study is supported partially by the National Natural Science Foundation of China (81571119 to Bo Hu and 81671147 to Huijuan Jin), New Century Excellent Talents in University (NCET-10-0406 to Bo Hu) and National Key Research \& Development Program of China (2018YFC1312200 to Bo Hu). The first funding body was involved in the design of the study; the second and third ones were involved in the collection, analysis, and interpretation of data; and the last one was involved in writing the manuscript.

\section{Availability of data and materials}

The datasets used or presented during this study are available from the corresponding author on reasonable request.

\section{Ethics approval and consent to participate}

The study was approved by the ethics committee for clinical trials of Tongj Medical College of Huazhong University of Science and Technology, China. Written informed consent was obtained from the participant.

\section{Consent for publication}

Written informed consent has been obtained from the patient for publication of this case report.

\section{Competing interests}

The authors declare that they have no competing interests.

\section{Author details}

'Department of Neurology, Union Hospital, Tongji Medical College, Huazhong University of Science and Technology, Wuhan 430022, China 2Department of Neurology, Caidian People Hospital, Wuhan 430100, China. ${ }^{3}$ Department of Pathology, Union Hospital, Tongji Medical College, Huazhong University of Science and Technology, Wuhan 430022, China. ${ }^{4}$ Department of Neuropathology, Beijing Neurosurgical Institute, Beijing, China

Received: 14 April 2019 Accepted: 20 September 2019

Published online: 23 October 2019

\section{References}

1. Rose D, Papa A, Tomao S, Greco E, Zacharias J. Cerebral metastases in patients with left atrial Myxoma. J Card Surg. 2016:31(5):289-93.

2. Badrisyah I, Saiful R, Rahmat H, Naik VR, Tan YC. Brain metastasis of atrial Myxoma: case report. Med J Malaysia. 2012;67(6):613-5.

3. Lee SJ, Kim JH, Na CY, Oh SS. Eleven years' experience with Korean cardiac myxoma patients: focus on embolic complications. Cerebrovascular Dis (Basel, Switzerland). 2012;33(5):471-9.

4. Jawaid A, Naqvi SY, Wiener R. Atrial myxoma presenting as acute ischaemic stroke and chronic right lower leg claudication. BMJ Case Rep. 2018;11(1). pii: e227427. https://doi.org/10.1136/bcr-2018-227427.

5. Kierdaszuk B, Gogol P, Kolasa A, Maj E, Zakrzewska-Pniewska B, Golebiowski $M$, et al. Multiple metastatic intracranial lesions associated with left atrial myxoma. Pol J Radiol. 2014;79:262-7.

6. Ekinci El, Donnan GA. Neurological manifestations of cardiac myxoma: a review of the literature and report of cases. Intern Med J. 2004:34(5):243-9.

7. Wen XY, Chen YM, Yu LL, Wang SR, Zheng HB, Chen ZB, et al. Neurological manifestations of atrial myxoma: a retrospective analysis. Oncol Lett. 2018; 16(4):4635-9.

8. Lee VH, Connolly HM, Brown RD Jr. Central nervous system manifestations of cardiac myxoma. Arch Neurol. 2007;64(8):1115-20.

9. Larsson S, Lepore V. Fau - Kennergren C, Kennergren C. atrial myxomas: results of 25 years' experience and review of the literature. Surgery. 1989;105(6):695-8.

10. Burton C, Johnston J. Multiple ceerebral aneurysms and cardiac myxoma. N Engl J Med. 1970;2822:35-6.

11. Fau DH, Seabra-Gomes R, da Silva JP, Damasio AR, Antunes JL, Antunes JL. Multiple cerebral aneurysms and cardiac myxoma. Arch Neurol. 1975;32: 269-70.
12. Connolly B, Prowse SJ, Connolly CE, Brett NJ. Heart or head?: a depression mimic delays diagnosis-oncotic cerebral aneurysms caused by atrial myxoma. BJR Case Rep. 2017;3(4):20170028.

13. Inayat F, Hussain A, Riaz I, Virk HUH. Atrial myxoma presenting as abdominal pain: an unusual association. BMJ Case Rep. 2019;12(2). pii: e228447. https:// doi.org/10.1136/bcr-2018-228447.

14. Radoi MP, Stefanescu F, Arsene D. Brain metastases and multiple cerebral aneurysms from cardiac myxoma: case report and review of the literature. Br J Neurosurg. 2012;26(6):893-5.

15. Asranna AP, Kesav P, Nagesh C, Sreedharan SE, Kesavadas C, Sylaja PN Cerebral aneurysms and metastases occurring as a delayed complication of resected atrial Myxoma: imaging findings including high resolution Vessel Wall MRI. Neuroradiology. 2017;59(5):427-9.

16. Mo R, Mi L, Zhou Q, Wang D. Outcomes of surgical treatment in 115 patients with primary cardiac tumours: a 15-year experience at a single institution. J Thorac Dis. 2017;9(9):2935-41.

17. Reynen K. Cardiac myxomas. N Engl J Med. 1995;333(24):1610-7.

18. Jr D, Frist WH, Stinson EB, Miller DC, Baldwin JC, Oyer PE, Jamieson S, et al. Primary cardiac neoplasms. Early and late results of surgical treatment in 42 patients. J Thorac Cardiovasc Surg. 1987;93(4):502-11.

19. Gerbode F, Kerth WJ, Hill JD, Hill JD. Surgical management of tumors of the heart. Surgery. 1967:61(1):94-101.

20. Blondeau P. Primary cardiac tumors--French studies of 533 cases. Thorac Cardiovasc Surg. 1990;38(Suppl 2):192-5.

21. Hanson EC, Gill CC, Razavi M, Loop FD. The surgical treatment of atrial myxomas. Clinical experience and late results in 33 patients. J Thorac Cardiovasc Surg. 1985;89(2):298-303.

22. Kumar A, Deopujari CE, Karmarkar VS. A rare diagnosis of multiple hemorrhagic metastases in brain. J Postgrad Med. 2011;57(3):214-7.

23. Al-Said Y, Al-Rached H, Baeesa S, Kurdi K, Zabani I, Hassan A. Emergency excision of cardiac myxoma and endovascular coiling of intracranial aneurysm after cerebral infarction. Case Rep Neurol Med. 2013;2013:839270.

24. Ezerioha N, Feng W. Intracardiac Myxoma, cerebral aneurysms and elevated Interleukin-6. Case Rep Neurol. 2015;7(2):152-5.

25. Jain S, Maleszewski JJ, Stephenson CR, Klarich KW. Current diagnosis and management of cardiac myxomas. Expert Rev Cardiovasc Ther. 2015;13(4): $369-75$

\section{Publisher's Note}

Springer Nature remains neutral with regard to jurisdictional claims in published maps and institutional affiliations.

Ready to submit your research? Choose BMC and benefit from:

- fast, convenient online submission

- thorough peer review by experienced researchers in your field

- rapid publication on acceptance

- support for research data, including large and complex data types

- gold Open Access which fosters wider collaboration and increased citations

- maximum visibility for your research: over $100 \mathrm{M}$ website views per year

At BMC, research is always in progress.

Learn more biomedcentral.com/submissions 